\title{
Van Rensselaer Potter: A Memoriam
}

GERALD M. LOWER, JR.

I first met Van Potter nearly 40 years ago when I was 17 and entering the University of Wisconsin as a new freshman. During the summer of 1963, Van was a participant in a series of evening seminars designed to familiarize premed students to the community at the University of Wisconsin Medical School. I was immediately struck by Van's unique ability to cut straight to the core of virtually any issue having to do with biomedicine. As with many of his students, I quickly found myself in a father-son relationship of both our making. Van has been a source of inspiration and guidance to me ever since.

Seven years later, as I was completing my doctorate at McArdle Laboratories, Van published his book Bioethics: Bridge to the Future. At the time, Van was not immune to criticism from his local peers for venturing into the realm of philosophy and ethics and not staying put in his laboratory. What his critics saw as a mistake to gossip about (so as to justify their lack of public involvement), I saw as Van's most profound and meaningful contribution. As a matter of history, the term "bioethics" was quickly picked up by the eastern medical community as a label for their own efforts to gain support for pursuing the ethics of an increasingly high-tech medicine. Programs in bioethics emerged all over America, and the term was popularized without even mentioning Van's name or his publications. So much for the ethics of American ethicists. To make matters worse, the type of bioethics promoted in America, pragmatic and nonconceptual, really bore little relationship to the bioethics that Van had in mind. Van published Global Bioethics: Building on the Leopold Legacy in 1988, and it was quickly admired, not at first by ethically bent Americans but by ethically bent Europeans. With international support, Global Bioethics has been able to establish a foothold south and north, east and west. If the world needs anything at present, it is a knowledge-based ethical morality, and Van's efforts have paved the way for the establishment of bioethics on a global basis. When the world gets around to seeing itself as a whole and looking for an intelligent ethics, Van Potter will still be around, it is certain.

Claude Bernard, pioneer of experimental medicine, was provided many acknowledgments for his research contributions, but Bernard himself felt that his greatest contributions to medicine were conceptual contributions, especially his distinction between the human internal and human external environments. In other words, Bernard's greatest contributions, in his own mind, were not factual but had more to do with how we see and how we think, concepts being infinitely more powerful than facts. The same is true with Van Potter. Notwithstanding the core importance of Global Bioethics, it is simply the case that 
Van's greatest contributions were conceptual contributions that have been largely unrecognized or ignored by a market-driven American biomedical community that has been operating for decades sans any cohesive biomedical philosophy, apparently believing that biomedicine is best defined by bean counters, lawyers, and policy wonks. As pointed out in the beginning by Aristotle, medicine is not a business but the highest calling of philosophy.

As a result, Van was always quick to point out that a viable ethics must be based on a viable scientific knowledge base, and the implications here are clear: a global ethics must be based on a global philosophy. In this regard, Van's original 1970 book contains several seminal insights that provide the basis for the emergence of just that-a global scientific philosophy embracing not only biological but cultural evolution.

In his chapter "The Role of the Individual in Modern Society," under the subsection "The Nature of Man and His Ideas," Van provides a diagram portraying the parallels between information flow and control at the biological and cultural levels of organization. The dynamic in this diagram is genomic and idealogic information, and this conceptualization can be moved through time as a function of the nature of emergent thought (inductive, deductive, reductive) and the nature of subsequent knowledge acquired (descriptive, mechanistic, systematic). This effort can be extended back two and a half millennia and placed within three-dimensional, hierarchical conceptual frameworks (space, time, matter) to fully illustrate the evolving conceptual embrace of the human mind and the changes in logic that accompany conceptual advances. Doing so allows full appreciation of the evolution of human thought within science. Examination of the impact of evolving scientific knowledge on traditional Western thought allows a full appreciation of the evolution of Western culture-an evolution that is quantifiable along a logarithmic spiral, from tribal ignorance and superstition to global human self-comprehension.

In his chapter "Survival as a Goal for Wisdom," under the subsection "Societal Competence as a Function of Wisdom and Knowledge," Van provides a two-dimensional diagram portraying the chronology and life span of scientists and philosophers and an accompanying theory of history. Once again, these conceptualizations can be integrated into evolutionary frameworks portraying the interaction of science with and the impact of science on traditional Western thought and political philosophy, from tribal totalitarianism to global democracy. In other words, if one seeks to know from whence we came, how we got to where we are, and where we might consider going, one has to begin with Van Potter. 